\title{
Unusual case of traumatic cervical internal carotid artery dissection presenting as pseudofenestration
}

\author{
Silvia Gesheva, ${ }^{1}$ Michael Timothy Bayona, ${ }^{2}$ Philipp Taussky, ${ }^{1}$ Ramesh Grandhi ${ }^{1}$
}

'Department of Neurosurgery, University of Utah, Salt Lake City, Utah, USA

${ }^{2}$ Department of Radiology, University of Utah Hospital, Salt Lake City, Utah, USA

Correspondence to Dr Ramesh Grandhi, ramesh.grandhi@hsc.utah.edu

Accepted 7 December 2018

\section{DESCRIPTION}

A 58-year-old man with no significant neurological history presented to the emergency department after being struck on the head and the back of the neck several times during an altercation 2 days earlier. At presentation, he had worsening headaches, blurry vision, nausea, vomiting and rightsided paresthesias.

Non-contrasted CT of the head and CT angiography (CTA) of the head and neck were obtained. The head CT and CTA did not indicate any injuries. CTA of the neck revealed a dissection with possible pseudoaneurysm of the left distal cervical internal carotid artery (ICA) (figure 1). The findings on MRI of the brain ruled out acute ischaemic changes. The patient was started on $325 \mathrm{mg}$ of aspirin daily. A subsequent digital subtraction angiography revealed fenestration of the high cervical segment of the left ICA (figures 2 and 3).

Congenital anomalies of the cervical ICA are very rare. Two anatomical variants described in literature are ICA duplication and fenestration. Duplication of the ICA is extremely rare and has been used to describe long segments with separate lumina involving the artery. Fenestration, on the other hand, describes a short focal segment of the artery with two lumina. A 'true' congenital cervical ICA fenestration has only been described in four cases in the literature. ${ }^{12}$ The embryological mechanism of 'true' ICA fenestration remains obscure, leading some authors to question its existence. Hasegawa $e t a l^{2}$ presented two cases of true cervical ICA fenestrations found incidentally during angiography, one in a patient with ruptured middle cerebral artery aneurysm and the other in a patient who presented with grand mal seizure and was found to
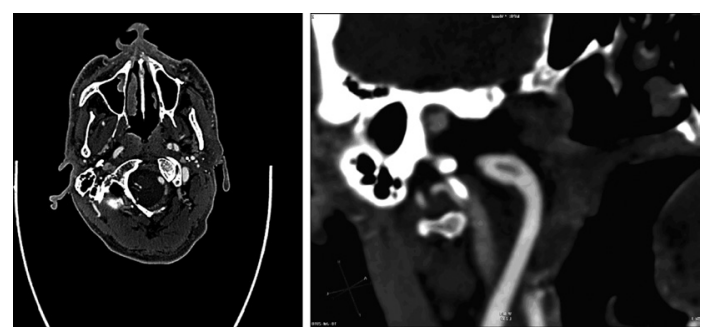

Figure 1 CT angiography (CTA) of the head and neck, axial views (left) and oblique reconstruction (right). On standard axial CTA, the ICA abnormality was reported as a dissection with possible pseudoaneurysm, which in this case is misleading, as seen on oblique reconstruction and conventional angiography. The oblique view is consistent with our angiographic findings as seen in figures 2 and 3. ICA, internal carotid artery.

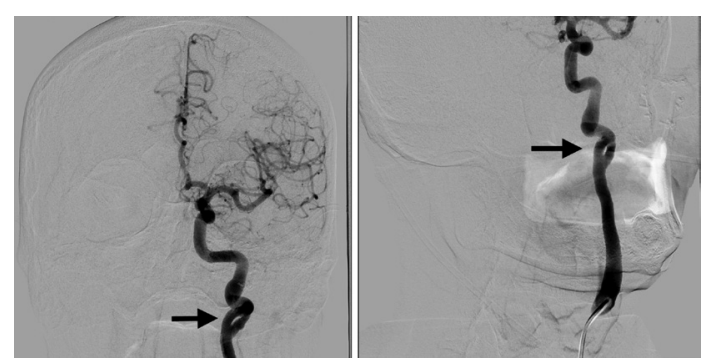

Figure 2 Digital subtraction angiography, left ICA injection, posteroanterior (left) and oblique (right) projections, reveals a pseudofenestration of the distal cervical ICA (arrows). The two limbs of the fenestration are patent and surprisingly regular in appearance. ICA, internal carotid artery.

have glioblastoma on CT/CTA imaging. In contrast, Gailloud et $a l^{3}$ published a series involving six patients with cervical ICA fenestration in the setting of fibromuscular dysplasia, trauma or previous diagnostic angiography, which they referred to as pseudofenestration.

Pseudofenestration of the ICA notably comes to attention in patients after transient ischaemic attacks (TIAs) or clinical thromboembolic or haemorrhagic events, as described in previous reports ${ }^{3}$ and as seen in our patient. Conversely, true fenestration is a normal anatomical variant that, to date, has only been discovered incidentally. Cervical ICA pseudofenestration has been associated with irregularities in the vessel lumen and aneurysmal dilatations. Our case is unique because the fenestrated segment of the ICA appeared very regular and

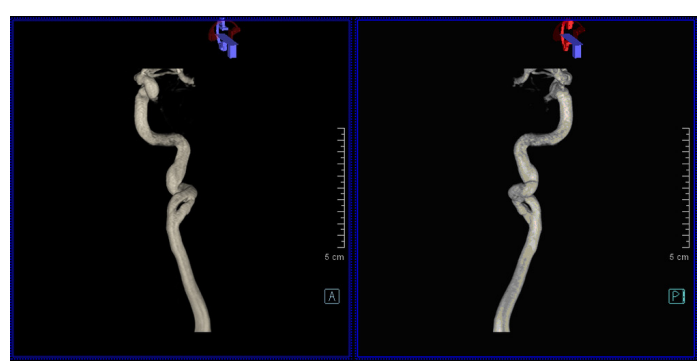

Figure 3 Spin angiography with threedimensional reconstruction of the left cervical ICA reveals the detailed anatomy of the pseudofenestration with no obvious dissection flaps and overall regular appearance of vessel lumen. Each limb of the fenestration measures approximately $3.5 \mathrm{~mm}$ in diameter, whereas the ICA proximal to the fenestration measures $5.6 \mathrm{~mm}$ and the ICA just distal to the fenestration is $5.8 \mathrm{~mm}$. ICA, internal carotid artery. 
both limbs were patent with smooth lumina. Our patient did have subjective symptoms consistent with TIAs; however, there was no radiographic evidence of acute infarction on MRI, and angiography showed lack of pseudoaneurysm, dissection and/or vessel wall irregularity that could account for the formation of thromboemboli.

Because of the rarity of this finding, there is no established treatment algorithm. In the case described herein, we kept the patient on aspirin and performed transcranial Doppler

\section{Learning points}

- A true cervical internal carotid artery (ICA) fenestration is a very rare anatomical variant; its diagnosis is made based on history and clinical presentation, in conjunction with conventional digital subtraction angiography.

- A pseudofenestration of the cervical ICA is a unique and unusual presentation of traumatic ICA dissection. These can be symptomatic, as in our patient, secondary to thromboembolic events.

- Treatment of cervical ICA pseudofenestration is usually conservative. sonography with emboli detection for three consecutive days. Given the lack of findings on MRI and no evidence of emboli, we discharged the patient on $325 \mathrm{mg}$ of aspirin daily. The patient has not experienced any further events.

Acknowledgements We thank Kristin Kraus for editorial assistance.

Contributors SG: reporting, drafting/revising, conception and design, acquisition/ analysis of data. MTB: acquisition/analysis of data, conception and design. PT: analysis of data, revising report, final approval. RG: reporting, drafting/revising report, conception and design, analysis of data, final approval.

Funding The authors have not declared a specific grant for this research from any funding agency in the public, commercial or not-for-profit sectors.

Competing interests PT is a consultant for Medtronic.

Patient consent Obtained.

Provenance and peer review Not commissioned; externally peer reviewed.

\section{REFERENCES}

1 Nakamura H, Yamada H, Nagao T, et al. Fenestration of the internal carotid artery associated with an ischemic attack-case report. Neurol Med Chir 1993;33:306-8.

2 Hasegawa T, Kashihara K, Ito H, et al. Fenestration of the internal carotid artery. Surg Neurol 1985;23:391-5.

3 Gailloud P, Carpenter J, Heck DV, et al. Pseudofenestration of the cervical internal carotid artery: a pathologic process that simulates an anatomic variant. AJNR Am J Neuroradiol 2004;25:421-4.

Copyright 2018 BMJ Publishing Group. All rights reserved. For permission to reuse any of this content visit

https://www.bmj.com/company/products-services/rights-and-licensing/permissions/

BMJ Case Report Fellows may re-use this article for personal use and teaching without any further permission.

Become a Fellow of BMJ Case Reports today and you can:

- Submit as many cases as you like

- Enjoy fast sympathetic peer review and rapid publication of accepted articles

- Access all the published articles

- Re-use any of the published material for personal use and teaching without further permission

For information on Institutional Fellowships contact consortiasales@bmjgroup.com

Visit casereports.bmj.com for more articles like this and to become a Fellow 